\title{
Continuous erector spinae plane block at lumbar level for relief of severe pain due to hip fracture: case series
}

\section{Bloqueo continuo del plano erector de la espina lumbar para manejo dell dolor severo por fractura de cadera: serie de casos}

\author{
Alejandro Tovar-Gutiérrez ${ }^{\mathrm{a}, \mathrm{b}}$ (D), Julio Ernesto Camelo-Rincón ${ }^{\mathrm{a}, \mathrm{b}}$, Óscar Iván Vásquez-Cómez ${ }^{\mathrm{a}, \mathrm{b}}$ \\ Adriana Margarita Cadavid-Puentes ${ }^{a, b}$ \\ a Pain Medicine Graduate Program, School of Medicine, Universidad de Antioquia. Medellín, Colombia. \\ ${ }^{b}$ Department of Anesthesiology and Pain Medicine, Hospital San Vicente Fundación. Medellín, Colombia. \\ Correspondence: Calle 64 No. 51D-154, Departamento de Anestesiología y Medicina del Dolor, Hospital San Vicente Fundación. Medellín, Colombia. \\ Email: adriana.cadavid@udea.edu.co \\ How to cite this article: Tovar-Cutiérrez A, Camelo-Rincón JE, Vásquez-Cómez Ól, Cadavid-Puentes AM. Continuous erector spinae plane block at lumbar \\ level for relief of severe pain due to hip fracture: case series. Colombian Journal of Anesthesiology. 2021;49:e962.
}

\section{Abstract}

\section{Introduction}

Hip fracture pain is frequently acute and disabling and increases perioperative complications in the patient; hence it requires a multimodal analgesia approach. This case series describes the continuous erector spinae plane block at the lumbar level for hip fracture analgesia.

\section{Methods}

A search was conducted of patients with hip fracture referred to the pain service of Hospital Universitario San Vicente Fundación (HUSVF) from August 2019 to March 2020, who had undergone continuous erector spinae plane block as part of their analgesic regimen.

\section{Results}

A total of 6 patients, 4 females and 2 males with an average age of 75 years were identified. A reduction in pain intensity from acute to mild or absent was observed in every case, up to 24 hours after the initial injection. $66 \%$ experienced a relapse of severe pain after 24 hours and 2 patients the catheter functionality failed after 24 hours. One patient underwent dermatome pinprick assessment.

\section{Conclusions}

The continuous erector spinae plane block with a single injection provided analgesic efficacy similar to other single injection peripheral blocks, although continuous analgesia for more than 24 hours was not achieved. Some variations in the block technique described may improve the analgesic effectiveness in patients with hip fracture pain.

\section{Keywords}

Pain; hip fracture; erector spinae plane block; multimodal analgesia; regional anesthesia. 


\section{Resumen}

\section{Introducción}

El dolor de la fractura de cadera suele ser fuerte e incapacitante y aumenta las complicaciones perioperatorias en el paciente, lo que hace indispensable el enfoque de analgesia multimodal. En esta serie de casos se describe la experiencia del bloqueo continuo del plano erector de la espina a nivel lumbar para analgesia en fractura de cadera.

\section{Métodos}

Se realizó una búsqueda de los pacientes con fractura de cadera remitidos al servicio de dolor del Hospital Universitario San Vicente fundación (HUSVF) desde agosto de 2019 hasta marzo de 2020, a quienes se les realizó bloqueo continuo del plano erector de la espina como parte de su esquema analgésico.

\section{Resultados}

Se encontraron 6 pacientes, 4 mujeres y 2 hombres, con una edad promedio de 75 años. Se observó reducción de la intensidad del dolor de fuerte a leve o ausente en todos los casos hasta las 24 horas posteriores a la inyección inicial. El $66 \%$ tuvo recaída del dolor fuerte posterior a las 24 horas y en 2 pacientes no se logró funcionalidad del catéter por más de 24 horas. En un paciente se hizo evaluación dermatómica por pinprick (prueba de pinchazo).

\section{Conclusiones}

El bloqueo continuo del plano erector de la espina con inyección única ofreció eficacia analgésica similar a otros bloqueos periféricos en inyección única, aunque no se logró analgesia continua con el catéter por más de 24 horas. Ciertas variaciones en la técnica del bloqueo descrita podrían mejorar la efectividad analgésica en pacientes con dolor por fractura de cadera.

\section{Palabras clave}

Dolor; fractura de cadera; erector de la espina; analgesia; anestesia regional.

\section{INTRODUCTION}

Pain following hip fracture is usually severe and disabling, in addition to increasing the risk of perioperative complications. (1) A multidisciplinary approach and management are required in susceptible populations. (2) Elderly patients present multiple comorbidities and receive multiple drug therapy, frequently resulting in drug interactions; moreover, the use of non-steroidal anti-inflammatory drugs and opioids is limited due to their adverse effects. $(3,4)$

Multimodal analgesia combines systemic analgesics with regional techniques. This practice improves patient safety by reducing the use of opioids, facilitating early mobilization, reducing the adynamic ileus and reducing gastrointestinal risks associated with other high-dose analgesics such as non- steroidal anti-inflammatory drugs. (5). The United Kingdom NICE guidelines and the American Society of Orthopedic Surgeons recommend regional analgesia such as the femoral block, the fascia iliaca or psoas compartment block in elderly patients with hip fracture. $(6,7)$

The anterior aspect of the hip has a nociceptive component innervated by the femoral, obturator and accessory obturator nerves; the posterior aspect has primarily a proprioceptive component innervated by the sciatic nerve. (8) Therefore, based on the anatomical model of the hip innervation, when considering regional analgesia in hip fracture, the choice should be a block that includes the femoral and obturator nerves. (9)

Among the regional approaches, the epidural technique used to be the standard for perioperative analgesia, to decrease chronic postoperative pain (POP), morbidity and mortality. (10) However, it is associated with significant adverse effects such as motor block, hypotension, urinary retention and anticoagulation difficulties. (11)

Recently, with the introduction of ultrasound as a support tool for regional anesthesia, more selective options have been developed, involving less adverse effects. The literature describes the femoral nerve block, and the fascia iliaca and psoas compartment nerve block. (12) More recently, the pericapsular nerve group block (PENG) was described by Cirón et al., (13) and the erector spinae plane (ESP) block described by Forero et al. (14) These blocks have shown single injection efficacy for hip fracture analgesia for up to 36 hours. However, time to definitive treatment of patients with hip fracture, from the time of admission, may exceed those 36 hours. Hence, placement of a continuous analgesia catheter would then be appropriate. In the case of continuous ESP block in the 
chest, analgesia efficacy data are already available from various surgical models. (15) Tulgar et al., (16) have described cases of lumbar ESP block for hip analgesia, using a visual analogue scale (VAS) of less than 3 , following surgery, with no need for rescue analgesia. The block assessment was done using the pinprick technique. (17) For this indication, the level described for the puncture was L4. (18)

The objective of this paper is to describe the experience with the continuous ESP block, for prolonged analgesia beyond 24 hours, in patients diagnosed with a hip fracture.

\section{METHODS}

Case series study. An active search was conducted to identify cases with a diagnosis of hip fracture, referred to the pain service of Hospital Universitario San Vicente Fundación de Medellín, from August 2019 to March 2020; the patients who underwent continuous lumbar ESP block were selected. This study was approved by the HUSVF Ethics in Institutional Research Committee (Minutes 22-2018).

The review of each case included sociodemographic variables, the type of fracture, the dynamic and at rest pain numerical scale, prior to the procedure, and then after 1, 14 and 48 hours. In the presence of delirium, the validated Spanish version of the PAINAD scale was used. (19)

\section{Lumbar ESP block at L4 technique}

The procedures were conducted under basic, non-invasive monitoring, including electrocardiography, pulse oximetry and blood pressure. The procedure was conducted by an anesthesiologist experienced in regional anesthesia, from the pain unit of the institution, after obtaining the signed informed consent.

A convex shz (Philips CX30) transducer was used for ultrasound guidance; a Touhy

FIGURE 1. Lumbar ESP block at L4.

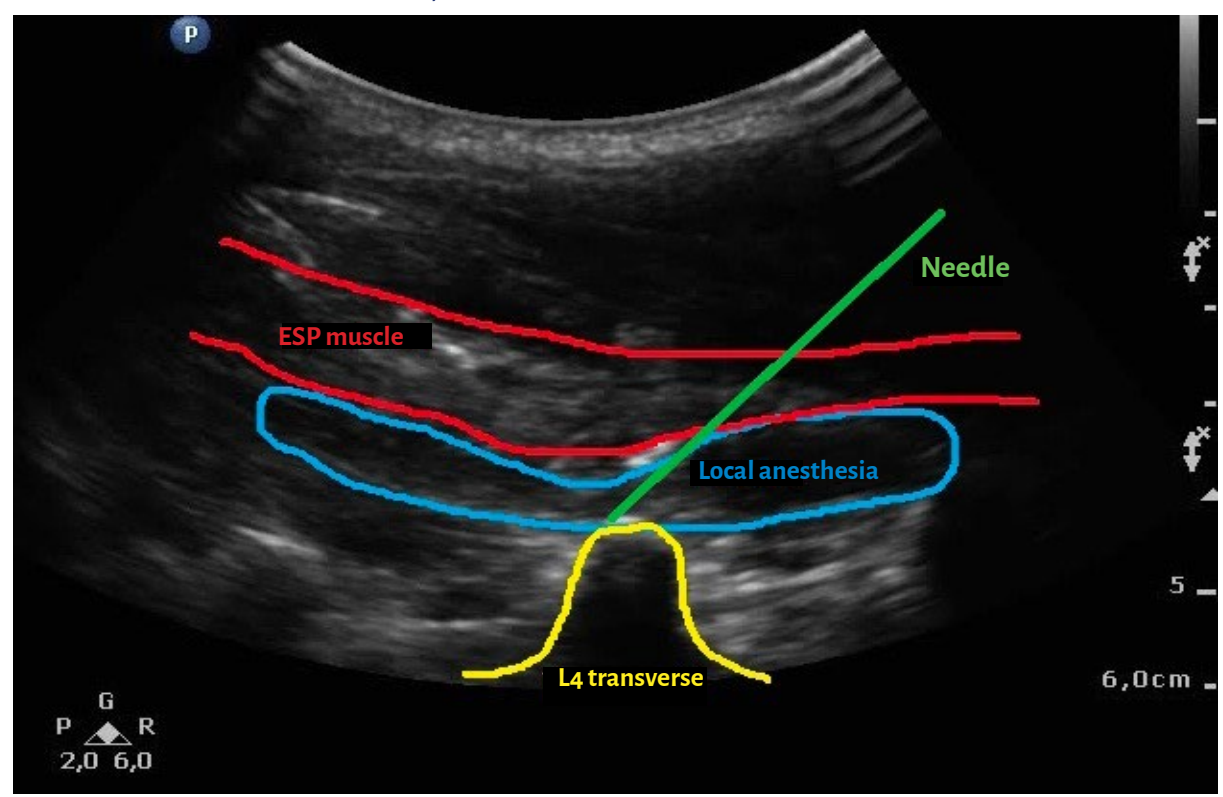

ESP: erector spinae plane. SouRCE: Authors.

FIGURE 2. Ultrasound changes in the elderly as a result of muscle fat degeneration and osteopenia.

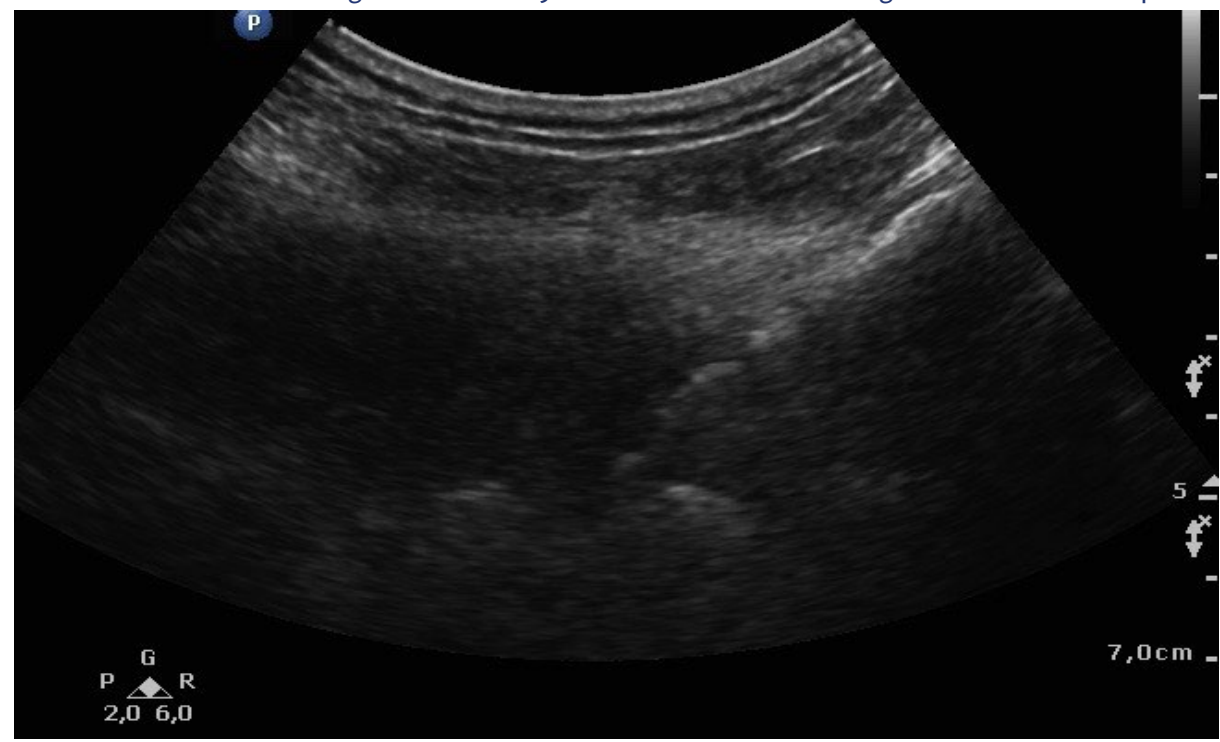

SOURCE: Authors.

18 g needle puncture was performed under local anesthesia, with an in-plane caudal to cephalic approach to make contact with the periosteum of the transverse process of $L 4$ deep into the ESP muscles; after negative aspiration for intravascular puncture, 20 $\mathrm{mL}$ of lidocaine at $2 \%$, without epinephrine were administered. Upon confirmation of the plane hydrodissection, a $22 \mathrm{~g}$ catheter was advanced, which was left behind at a depth of $5 \mathrm{~cm}$ inside the ESP (Figures 1 y 2).

\section{Assessment}

The sensory block was assessed 30 minutes later using the pinprick technique. (17) Both the static and dynamic pain was recorded on the numerical pain scale $1 \mathrm{~h}, 24 \mathrm{~h}$ and $48 \mathrm{~h}$ after the block. The dynamic pain was measured elevating the affected extremity at 15 degrees, as described by Farrar. (20) $0.125 \%$ bupivacaine was infused using a computerized pump (Sapphire) with 
automatic $20 \mathrm{~mL}$ boluses every 6 hours, and continuous $1 \mathrm{~mL} / \mathrm{h}$ infusion (to prevent catheter occlusion). No adverse effects were documented during the procedure.

\section{CASE SERIES}

The case series comprised 6 patients, 4 females and 2 males, with a mean age of
75.5 years \pm 23 years $(1 S D)$. The principal diagnoses are shown in Table 1.

Pinprick dermatome distribution assessment was conducted in one patient using 2 dermatomes (L2 and L3). Most patients were senile, with underlying pathologies such as multifactorial fluctuating delirium.

The baseline numerical pain scale was in average $9 \pm 0.8$. One hour post-block, the mean static pain was $2 \pm 1.1$, and the

TABLE 1. Demographic characteristics of the patients with hip fracture, who underwent a continuous ESP block.

\begin{tabular}{|c|c|c|c|c|c|c|}
\hline Subject & Sex & Age & Type of fracture & Comorbidities & $\begin{array}{l}\text { Catheter } \\
\text { duration }\end{array}$ & $\begin{array}{c}\text { Catheter } \\
\text { complications }\end{array}$ \\
\hline 1 & $\mathrm{~F}$ & 91 & $\begin{array}{l}\text { Intertrochanteric } \\
\text { right femur }\end{array}$ & $\begin{array}{l}\mathrm{HBP}, \mathrm{AV} \text { block } \mathrm{AV} \\
\text { grade } 1 \text {, delirium }\end{array}$ & $48 \mathrm{~h}$ & No \\
\hline 2 & $\mathrm{~F}$ & 92 & $\begin{array}{l}\text { Intertrochanteric } \\
\text { left femur }\end{array}$ & HBP, delirium & $48 \mathrm{~h}$ & No \\
\hline 3 & $\mathrm{~F}$ & 79 & $\begin{array}{l}\text { Intertrochanteric } \\
\text { right femur }\end{array}$ & $\begin{array}{l}\text { HBP, COPD, CHF, } \\
\text { DM 2, delirium }\end{array}$ & $48 \mathrm{~h}$ & No \\
\hline $4^{*}$ & M & 77 & $\begin{array}{l}\text { Right } \\
\text { acetabulum }\end{array}$ & $\begin{array}{c}\text { HBP, DM 2, } \\
\text { cirrhosis, coronary } \\
\text { disease, delirium }\end{array}$ & $24 \mathrm{~h}$ & $\begin{array}{c}\text { Accidental } \\
\text { dislodgement }\end{array}$ \\
\hline 5 & $M$ & 24 & $\begin{array}{l}\text { Intertrochanteric } \\
\text { left femur }\end{array}$ & No & $48 \mathrm{~h}$ & No \\
\hline $6 \%$ & $\mathrm{~F}$ & 90 & $\begin{array}{l}\text { Intertrochanteric } \\
\text { right femur }\end{array}$ & $\begin{array}{l}\text { HBP, CVA seque- } \\
\text { lae, osteoporosis, } \\
\text { delirium }\end{array}$ & $24 \mathrm{~h}$ & $\begin{array}{l}\text { Catheter } \\
\text { removal due to } \\
\text { obstruction }\end{array}$ \\
\hline
\end{tabular}

"Accidental catheter dislodgement at 24 hours, "Dysfunctional catheter removed at 24 hours. AV: Auriculoventricular; CHF: Congestive Heart Failure; COPD: Chronic Obstructive Pulmonary Disease; CVA: Cerebrovascular accident; DM: Diabetes mellitus; ESP: Erector Spinae Plane; HBP: High Blood Pressure.

SOURCE: Authors.

FigURE 3. Numerical dynamic pain assessment scale at 4 time-periods of follow-up.

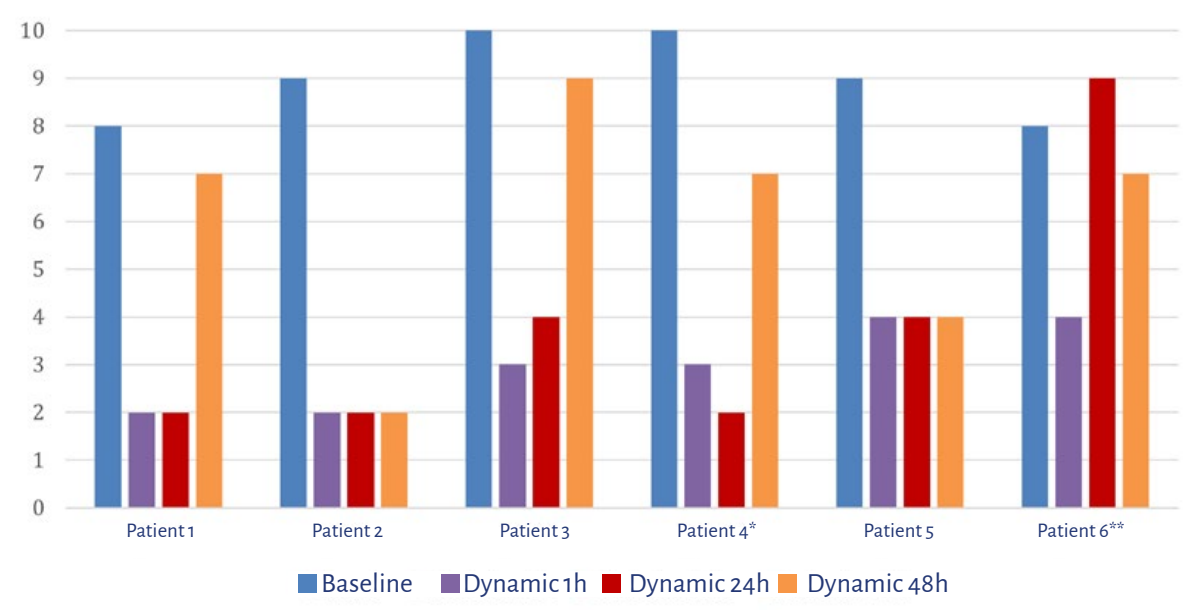

*Accidental catheter dislodgement at 24 hours, ${ }^{* *}$ Dysfunctional catheter removed at 24 hours.

SOURCE: Authors. dynamic pain was $3 \pm 0.8$. At 24 hours, the static pain was $2.8 \pm 2.5$ and the dynamic was $3.8 \pm 2.4$; at 48 hours, the static pain was $4.2 \pm 2.2$ and the dynamic was $5.25 \pm 2.5$ (Figure 3).

\section{Case 1}

91-year-old femalewith rightintertrochanteric femur fracture (IFF), a history of hypertension (HBP), first degree AV block and delirium, with acute pain secondary to fracture. The patient underwent a US-guided continuous lumbar ESP block at L4, with a duration of 48 hours. The dermatome level could not be assessed because of delirium.

\section{Case 2}

92-year-old female with left IFF, a history of HBP and delirium, with acute pain secondary to fracture. The patient underwent US-guided continuous lumbar ESP block at L4, with a duration of 48 hours. The dermatome level could not be assessed because of delirium.

\section{Case 3}

79-year-old female with right IFF, a history of HBP, COPD, chronic cardiac failure, diabetes mellitus type 2 (DM 2) and delirium. The patient experienced acute pain, secondary to fracture and underwent US-guided continuous lumbar ESP block at L4, which lasted for 48 hours. The dermatome level could not be assessed because of delirium.

\section{Case 4}

77-year-old male, with right acetabular fracture, history of HBP, DM 2, cirrhosis, coronary disease and delirium, with severe pain secondary to fracture. The patient underwent US-guided continuous lumbar ESP block at L4, which lasted for 24 hours. The dermatome level could not be assessed 
because of delirium; the accidentally dislodged the catheter at 24 hours.

\section{Case 5}

24-year-old male with a diagnosis of left IFF, with no history of disease and acute pain secondary to fracture. The patient underwent US-guided continuous lumbar ESP block at L4, which lasted for 48 hours. Dermatome assessment was performed at levels L2-L3 using the pinprick technique.

\section{Case 6}

90-year-old female, with a diagnosis of right intertrochanteric femur fracture, history of HBP, CVA sequelae, osteoporosis and delirium. The patient experienced acute pain secondary to fracture and underwent US-guided continuous lumbar ESP block at L4, which lasted for 24 hours. The dermatome level could not be assessed because of delirium. The catheter was removed at 24 hours because of dysfunctionality-obstruction.

\section{DISCUSSION}

Patientswith hip fracture usually experience acute pain. Multimodal analgesia which combines systemic analgesics with regional techniques, improves patient safety by reducing the intake of opioids, facilitating early ambulation and reducing the paralytic ileus. Furthermore, it contributes to reduce the risk of gastrointestinal complications such as bleeding, associated with high doses of analgesics such as non-steroidal anti-inflammatory drugs. (5)

The ESP is a newly described regional analgesic technique with a growing number of indications in clinical practice. (21-23) For hip fracture analgesia, this case series of lumbar ESP block illustrates a reduction of pain from acute to mild or absent, following the block (VAS 3 or less) for up to $24 \mathrm{~h}$. However, 4 of the 6 cases managed with continuous catheter following the ESP block experienced acute pain relapse (defined as VAS $\geq 7$ ) after 24 hours. Catheter dysfunction was observed in 2 cases, due to obstruction and accidental dislodgement, and the catheters had to be removed after 24 hours.

The results of the lumbar ESPB single injection in this case series for hip analgesia are comparable to the fascia iliaca block and to PENG blog, with a pain reduction from severe to mild, following a single injection. $(23,24)$ It should be highlighted that though in most patients in this series severe pain was observed after 24 hours, the single injection Tulgar technique block is a valuable therapeutic option in institutions that don't have a pain unit for proper assessment and surveillance of these catheters. This statement is supported by cases reporting up to 36 hours of analgesia following single injection blocks. (12) These blocks are also able to decrease the use of opioids, particularly in this senile population at higher risk of experiencing adverse effects secondary to systemic analgesia. $(3,4)$

In accordance with Tulgar et al., in his original series of 12 cases with ESP block for hip fracture analgesia, this study supports the reduction from acute to mild pain following a single injection, with a VAS score of less than 3 in 11 patients. (25) Additionally, in one patient the same author assessed volume dispersion using contrast medium and CT and found coverage from the transverse process into the psoas, mainly at the level of L3-L4-L5, proximal to the femoral and obturator nerves on the same side of the block.

In continuous catheter analgesia following lumbar ESP block in hip surgery, Bugada et al (26) describe 273 and 80-yearold patient undergoing continuous block at L4, advancing the catheter from caudal to cephalic and administering programmed boluses and continuous infusion. In both cases, the analgesia was reported as satisfactory for up to 48 hours after the catheter. This case prompted us to try to achieve the same result for the treatment of hip fracture-associated pain, following the injection technique previously described by Tulgar et al. However, in most cases, a severe pain relapse was observed after 24 hours with the catheter, following the ESP block. Consequently, we do believe that a different ESP block approach should be considered.

The high rate of therapeutic failure in our experience, may be explained by different reasons. The anatomy of the lumbar region differs with regards to the observations in the thoracic approach initially described by Forero et al., (14) with respect to the erector spinae plane muscles. Based on the sonoanatomy, the ESP muscles in the lumbar region are thicker, indicating greater depth for the advancement of the needle and increased risk of losing visualization.

Moreover, during the hydrodissection technique in the ESP block to create the compartment to lodge the catheter, and contrary to the thoracic approach, creating this compartment at the lumbar level is difficult due to the heavier weight and larger size of the muscles. (27) We also found that advancing the catheter from the tip of the needle to the longitudinal ESP axis is more difficult, because the angle is narrower and because of the depth of the lumbar transverse process.

Furthermore, the elderly population, which is the majority in these case series, exhibit aging-associated changes in the lumbar ESP sonoanatomy, such as muscle fat degeneration, osteoporotic thinning of the lumbar transverse process, and these findings make the block technique more difficult. (28)

Whilst the first erector spinae plane block described by Tulgar et al, was able to assess the sensitive level of dermatomes from $T 12$ to $L 4$, in our case series it was only possible to show the sensitive block level using the dermatome pinprick test in one patient. This was the only young patient in the series. In the rest of the patients, due to their old age and underlying delirium, it was impossible to objectively assess dermatome hypoesthesia. 
This difficulty for dermatome testing contrasts with our previous experience with the thoracic ESP block, where we were able to identify hypoesthesia with the pinprick test, half an hour after the block in $80 \%$ of the cases, with satisfactory analgesia. $(21,22)$

The results for continuous analgesia herein discussed, with a high rate of catheter failure following the ESP block, encouraged us to review other techniques for future applications, such as the one recently described by Darling et al. (29) These authors discuss a case in which following a failed lumbar plexus block for hip surgery, an ESP block was performed from T8, advancing the catheter to $\mathrm{T} 12$, with a cranial to caudal approach, checking the level of sensation from $T 10$ to $L 4$ with analgesic effectiveness of the catheter up to the fourth postoperative day. (29) The anatomy of the thoracic paraspinal muscles would facilitate the hydrodisection of the compartment and hence the advancement of the catheter. (29)

This paper has several limitations and one of them is the lack of a control group. The old age of patients with hip fracture, their cognitive decline and fluctuating delirium make it difficult to assess the dermatome block following the initial ESP block injection. Only one of the 6 cases examined could be documented.

In this case series of lumbar ESP block for hip fracture analgesia, the single injection showed analgesic efficacy, reducing the level pain from severe to mild. After 24 hours of continuous catheter infusion, most of our patients experienced a relapse of acute pain. Variations in the lumbar ESPB technique and continuous analgesia should be considered, to improve the duration of analgesia in patients with acute hip fracture pain.

\section{ETHICAL DISCLOSURES}

\section{Ethics committee approval}

This study was approved by the Institutional Ethics in Research Committee - Hospital San Vicente Fundación (Minutes 22-2018).

\section{Protection of human beings and animals}

The authors declare that the procedures used in this study followed the ethical standards for experiments in humans and were consistent with the World Medical Association and the Declaration of Helsinki.

\section{Confidentiality of the data}

The authors declare they followed the necessary protocols and processes to protect the identity of the subjects.

\section{Right to privacy and informed consent}

The authors obtained the corresponding ethical authorizations to collect the necessary information to write this paper, and the privacy of the subjects included was preserved. The document is under custody of the corresponding author.

\section{ACKNOWLEDGEMENTS}

\section{Contribution by the authors}

AT: Planning of the study, data collection, interpretation of the results and drafting of the manuscript.

JC: Planning of the study, data collection, interpretation of the results and analysis of the data

OV: Interpretation of the results and drafting of the manuscript

AC: Inception of the original project, planning of the study, interpretation of the results and drafting and approval of the final manuscript.

\section{Study assistance}

None declared.

\section{Financial support and sponsorship}

None declared.

\section{Financing}

The authors declare that no funding was received to prepare this report.

\section{Conflict of interests}

The authors have no conflict of interests to disclose.

\section{Presentations}

None declared.

\section{Acknowledgements}

None declared.

\section{REFERENCES}

1. Bhandari M, Swiontkowski M. Management of acute hip fracture. N Engl ] Med. 2017;377:2053-62. doi: http://doi.org/10.1056/ NEJMcp1611090

2. Hsu JR, Mir H, Wally MK, Seymour RB. Clinical practice guidelines for pain management in acute musculoskeletal injury. J Orthopaedic Trauma. 2019;33:e158-82. doi: http://doi. org/10.1097/BOT.0000000000001430

3. Schug SA, Palmer GM, Scott DA, Halliwell R, Trinca ]. Acute pain management: scientific evidence, fourth edition, 2015. Med ] Aust. 2016;204(8):315-7. doi: http://doi.org/10.5694/ mja16.00133

4. Adunsky A, Levy R, Mizrahi E, Arad M. Exposure to opioid analgesia in cognitively impaired and delirious elderly hip fracture patients. Arc Cerontol Ceriatr. 2002;35(3):245-51. doi: http://doi. org/10.1016/s0167-4943(02)00044-4

5. Zhou J, Fan Y, Zhong J, Wen X, Chen X. Efficacy and safety of multimodal analgesic techniques for preventing chronic postsurgery pain under different surgical categories: a meta-analysis. Sci Rep. 2017;7: 678. doi: http:// doi.org/10.1038/s41598-017-00813-5

6. Swift C, Chesser T, Field A, Griffiths R, Handley R, Hertz K, et al. The management of hip fracture in adults - NICE guideline. 2010;(October):27. 
7. Brox WT, Roberts KC, Taksali S, Wright DG, Wixted J], Tubb CC, et al. The American Academy of Orthopaedic Surgeons evidence-based guideline on management of hip fractures in the elderly. ] Bone Joint Surg Am. 2015;97(14):1196-9. doi: http://doi.org/10.2106/ $\underline{\text { JBJS.0.00229 }}$

8. Gerhardt M, Johnson K, Atkinson R, Snow B, Shaw C, Brown A, et al. Characterisation and classification of the neural anatomy in the human hip joint. HIP International. 2012;22(1):75-81. doi: http://doi.org/10.5301/ HIP.2012.9042

9. Short A], Barnett J]G, Cofeld M, Baig E, Lam $\mathrm{K}$, Agur AMR, et al. Anatomic study of innervation of the anterior hip capsule implication for image-guided intervention. Reg Anesth Pain Med. 2018;43:186-92. doi: http://doi. org/10.1097/AAP.0000000000000701

10. Narinder R. Epidural technique for postoperative pain: gold standard no more? Reg Anesth Pain Med. 2012;37(3):310-7. doi: http://doi. org/10.1097/AAP.ob013e31825735c6

11. Chou R, Gordon DB, De Leon-Casasola OA, Rosenberg JM, Bickler S, Brennan T, et al. Management of postoperative pain: A clinical practice guideline from the American pain society, the American society of regional anesthesia and pain medicine, and the American society of anesthesiologists' committee on regional anesthesia, executive commi. J Pain. 2016;17(2):131-57. doi: http://doi.org/10.1016/j. jpain.2015.12.008

12. Abou-Setta AM, Beaupre LA, Rashiq S, Dryden D, Hamm MP, Sadowski CA, et al. Comparative effectiveness of pain management interventions for hip fracture: A systematic review. Ann Intern Med. 2011;155:234-45. doi: http://doi.org/10.7326/0003-4819-155-4201108160-00346

13. Girón-Arango L, Peng P, Chin K, Brull R, Perlas A. Pericapsular nerve group (PENG) block for hip fracture. Reg Anesth Pain Med. 2018;43(8):859-63. doi: http://doi.org/10.1097/ AAP.0000000000000847

14. Forero M, Adhikary SD, López H, Tsui C, Chin KJ. The erector spinae plane block a novel analgesic technique in thoracic neuropathic pain. Reg Anesth Pain Med. 2016;41(5):621-7. doi: http://doi.org/10.1097/ AAP.0000000000000451

15. Kot P, Rodríguez P, Granell M, Cano B, Rovira $L$, Morales ], et al. The erector spinae plane block: A narrative review. Korean ] Anesthesiol. 2019;72(3):209-20. doi: http://doi. org/10.4097/kja.d.19.00012.

16. Tulgar S, Senturk O. Ultrasound guided erector spinae plane block at L-4 transverse process level provides effective postoperative analgesia for total hip arthroplasty. ] Clin Anesth. 2017;44:68. doi: http://doi.org/10.1016/j.jclinane.2017.11.006.

17. Abraham A, Alabdali M, Alsulaiman A, Albulaihe $\mathrm{H}$, Breiner $A$, Katzberget $H$, al. The sensitivity and specificity of the neurological examination in polyneuropathy patients with clinical and electrophysiological correlations. PLoS One. 2017;12(3):e0171597. doi: http://doi. org/10.1371/journal.pone.0171597

18. Tulgar S, Ermis MN, Ozer Z. Combination of lumbar erector spinae plane block and transmuscular quadratus lumborum block for surgical anaesthesia in hemiarthroplasty for femoral neck fracture. Indian ] Anaesth. 2018;62:8025. doi: http://doi.org/10.4103/ija.IJA_230_18

19. García-Soler A, Sánchez-Iglesias I, Buiza C, Alaba J, Navarro AB, Arriola E, et al. Adaptación y validación de la versión española de la escala de evaluación de dolor en personas con demencia avanzada: PAINAD-Sp. Rev Esp Ceriatr Gerontol. 2014;49(1):10-4. doi: http://doi. org/10.1016/j.regg.2013.02.001

20. Farrar JT, Berlin JA, Strom BL. Clinically important changes in acute pain outcome measures: a validation study. ] Pain Symptom Manage. 2003;25(5):406-11. doi: http://doi. org/10.1016/s0885-3924(03)00162-3

21. Forero $M$, Rajarathinam $M$, Adhikary $S$, Chin K]. Continuous erector spinae plane block for rescue analgesia in thoracotomy after epidural failure. A A Case Reports. 2017;8(10):254-6. doi: http://doi.org/10.1213/ XAA.0000000000000478
22. Barrios A, Camelo ], Gómez ], Forero M, Peng $P$, Visbal K, et al. Evaluation of sensory mapping of erector spinae plane block. Pain Physician. 2020;23(3):E289-96.

23. Castillón P, Veloso M, Gómez O, Salvador ], Bartra A, Anglés F. Fascia iliaca block for pain control in hip fracture patients. Rev Esp Cir Ortop Traumatol. 2017;61(6):383-9. doi: http:// doi.org/10.1016/j.recot.2017.07.004

24. Kukreja P, Avila A, Northern T, Dangle ], KoIli S, Kalagaraet $\mathrm{H}$. A retrospective case series of pericapsular nerve group (PENG) block for primary versus revision total hip arthroplasty analgesia. Cureus. 2020;12(5):e8200. doi: http://doi.org/10.7759/cureus.8200

25. Tulgar S, Selvi O, Senturk O, Nurullah Ermis M, Cubuk R, Ozer Z. Clinical experiences of ultrasound-guided lumbar erector spinae plane block for hip joint and proximal femur surgeries. J Clin Anesth. 2018;47:5-6. doi: http://doi. org/10.1016/j.jclinane.2018.02.014

26. Bugada D, Zarcone AG, Manini M, Lorini LF. Continuous erector spinae block at lumbar level (14) for prolonged postoperative analgesia after hip surgery. ] Clin Anesth. 2019;52:24-25. doi: http://doi.org/10.1016/j. jclinane.2018.08.023

27. Ivanusic ], Konishi Y, Barrington M]. A cadaveric study investigating the mechanism of action of erector spinae blockade. Reg Anesth Pain Med. 2018;43(6):567-71. doi: http://doi. org/10.1097/AAP.0000000000000789

28. Henderson M, Dolan J. Challenges, solutions, and advances in ultrasound-guided regional anaesthesia. B]A Educ. 2016;16(11):374-80. doi: http://doi.org/10.1093/bjaed/mkw026

29. Darling CE, Pun SY, Caruso T], Tsui BC. SuCcessful directional thoracic erector spinae plane block after failed lumbar plexus block in hip joint and proximal femur surgery. ] Clin Anesth. 2018;49:1-2. doi: http://doi.org/10.1016/j.jclinane.2018.05.002. 